\title{
Free vibration of laminated composite plates by the various shear deformation theories
}

\author{
Song Xiang ${ }^{1, a^{*}}$, Chun $\mathrm{Lu}^{2, \mathrm{~b}}$, Ji Wang ${ }^{1, \mathrm{c}}$, Wei-ping Zhao ${ }^{1, \mathrm{~d}}$ \\ ${ }^{1}$ Liaoning Key Laboratory of General Aviation, Shenyang Aerospace University, No. 37 Daoyi \\ South Avenue, Shenyang, Liaoning 110136, People's Republic of China \\ ${ }^{2}$ Faculty of Aerospace Engineering, Shenyang Aerospace University, No. 37 Daoyi South Avenue, \\ Shenyang, Liaoning 110136, People's Republic of China \\ axs74342@sina.com, b2372178@qq.com, cxiaoji55314@163.com, ${ }^{\mathrm{d}}$ 2535693329@qq.com
}

Keywords: Vibration; Laminated composite plates; Shear deformation theories; Natural frequency. Abstract. In this paper, the analysis of various higher-order shear deformation theories for the free vibration of laminated composite plates is presented. A Navier-type analytical method was used to solve the governing differential equations. Natural frequencies of simply supported laminated composite plates are calculated. The present results are compared with the available published results.

\section{Introduction}

The use of laminated composite has generally increased in weight sensitive applications such as aerospace and automotive structures due to their low maintenance cost and high strength-to-weight ratio. The vibration problem of laminated composite structures has attracted the attention of many researchers.

Sahoo and Singh [1] proposed a new trigonometric zigzag theory for the analysis of laminated composite and sandwich plates. Ngo-Cong et al. [2] presented a new effective radial basis function (RBF) collocation technique for the free vibration analysis of laminated composite plates using the first order shear deformation theory (FSDT).

In this paper, the theories of Touratier [3], Mantari [4], Karama [5], Levinson [6] are used to study the free vibration behavior of laminated composite plates. The governing differential equations are solved by a navier-type analytical method. The present results are compared with the available published results.

\section{Governing equations and boundary conditions}

Considering a plate of uniform thickness $\mathrm{h}$. According to the higher order shear deformation theory, the displacement field is given as:

$$
\begin{aligned}
& U=u(x, y)-z \frac{\partial w(x, y)}{\partial x}+f(z) \phi_{x}(x, y) \\
& V=v(x, y)-z \frac{\partial w(x, y)}{\partial y}+f(z) \phi_{y}(x, y) \\
& W=w(x, y)
\end{aligned}
$$

The transverse shear function in Touratier [3] is:

$$
f(z)=\frac{h}{\pi} \sin \left(\frac{\pi z}{h}\right)
$$

The transverse shear function in Mantari [4] is:

$$
f(z)=\sin \left(\frac{\pi z}{h}\right) e^{\frac{1}{\cos \left(\frac{\pi z}{h}\right)}}+\frac{\pi}{2 h} z
$$

The transverse shear function in Karama [5] is:

$$
f(z)=z e^{-2(z / h)^{2}}
$$


The transverse shear function in Levinson [6] is:

$$
f(z)=z\left(1-\frac{4 z^{2}}{3 h^{2}}\right)
$$

By substituting the displacement field into the strain-displacement relationships, the following strain components can be write as:

$$
\begin{aligned}
& \varepsilon_{x}=\frac{\partial u}{\partial x}-z \frac{\partial^{2} w}{\partial x^{2}}+f(z) \frac{\partial \phi_{x}}{\partial x} \\
& \varepsilon_{y}=\frac{\partial v}{\partial y}-z \frac{\partial^{2} w}{\partial y^{2}}+f(z) \frac{\partial \phi_{y}}{\partial y} \\
& \gamma_{x y}=\frac{\partial u}{\partial y}+\frac{\partial v}{\partial x}-2 z \frac{\partial^{2} w}{\partial x \partial y}+f(z)\left(\frac{\partial \phi_{x}}{\partial y}+\frac{\partial \phi_{y}}{\partial x}\right) \\
& \gamma_{y z}=\frac{d f(z)}{d z} \phi_{y} \\
& \gamma_{x z}=\frac{d f(z)}{d z} \phi_{x}
\end{aligned}
$$

By the principle of virtual displacements, the Euler-Lagrange equations can be:

$$
\begin{aligned}
& \frac{\partial N_{x}}{\partial x}+\frac{\partial N_{x y}}{\partial y}=I_{1} u_{, t t}+I_{4} \phi_{x, t t}-I_{2} \frac{\partial w}{\partial x}, t t \\
& \frac{\partial N_{y}}{\partial y}+\frac{\partial N_{x y}}{\partial x}=I_{1} v_{, t t}+I_{4} \phi_{y, t t}-I_{2} \frac{\partial w}{\partial y}{ }_{, t t} \\
& \frac{\partial^{2} M_{x}}{\partial x^{2}}+\frac{\partial^{2} M_{y}}{\partial y^{2}}+2 \frac{\partial^{2} M_{x y}}{\partial x \partial y}=I_{2} \frac{\partial u}{\partial x_{, t t}}+I_{2} \frac{\partial v}{\partial y_{, t t}}+I_{1} w_{, t t}-I_{3}\left(\frac{\partial^{2} w}{\partial x^{2}}+\frac{\partial^{2} w}{\partial y^{2}}\right)_{, t t}+I_{5}\left(\frac{\partial \phi_{x}}{\partial x}+\frac{\partial \phi_{y}}{\partial y}\right)_{, t t} \\
& \frac{\partial M_{x}^{f}}{\partial x}+\frac{\partial M_{x y}^{f}}{\partial y}-Q_{x}^{f}=I_{4} u_{, t t}+I_{6} \phi_{x, t t}-I_{5} \frac{\partial w}{\partial x}{ }_{, t t} \\
& \frac{\partial M_{y}^{f}}{\partial y}+\frac{\partial M_{x y}^{f}}{\partial x}-Q_{y}^{f}=I_{4} v_{, t t}+I_{6} \phi_{y, t t}-I_{5} \frac{\partial w}{\partial y_{, t t}}
\end{aligned}
$$

\section{Navier methods}

The simply supported boundary conditions and the governing equations are satisfied by the following displacement functions.

$$
\begin{aligned}
& u=\sum_{m=1}^{\infty} \sum_{n=1}^{\infty} U_{m n} \cos (\alpha x) \sin (\beta y) e^{i \omega t} \\
& v=\sum_{m=1}^{\infty} \sum_{n=1}^{\infty} V_{m n} \sin (\alpha x) \cos (\beta y) e^{i \omega t} \\
& w=\sum_{m=1}^{\infty} \sum_{n=1}^{\infty} W_{m n} \sin (\alpha x) \sin (\beta y) e^{i \omega t} \\
& \phi_{x}=\sum_{m=1}^{\infty} \sum_{n=1}^{\infty} X_{m n} \cos (\alpha x) \sin (\beta y) e^{i \omega t} \\
& \phi_{y}=\sum_{m=1}^{\infty} \sum_{n=1}^{\infty} Y_{m n} \sin (\alpha x) \cos (\beta y) e^{i \omega t}
\end{aligned}
$$


where $\alpha=\frac{m \pi}{a}, \beta=\frac{n \pi}{b}, \omega$ is the natural circular frequency. Substituting Eq. (8) into Eq. (7) and collecting the coefficients, we can obtain the following equation:

$$
\left[K-\omega^{2} M\right]\{\Delta\}=\{0\},\{\Delta\}^{T}=\left\{U_{m n}, V_{m n}, W_{m n}, X_{m n}, Y_{m n}\right\}
$$

The natural circular frequency $\omega$ can be obtained by solving the eigenvalue equations (9).

\section{Numerical examples}

Here all layers of the laminated plates are the same material properties, the lamina properties are assumed to be:

$$
\frac{E_{1}}{E_{2}}=10,20,30,40 ; G_{12}=G_{13}=0.6 E_{2} ; G_{23}=0.5 E_{2} ; v_{12}=0.25 ; \rho=1
$$

The dimensionless natural frequencies are given by

$$
\bar{\omega}=\frac{\omega a^{2}}{h} \sqrt{\frac{\rho}{E_{2}}}
$$

Table 1 lists the non-dimensional fundamental frequency of the simply supported laminate plate of various modulus ratios of $E_{1} / E_{2}$ and side-to-thickness ratio $a / h$. It is found that the results are in very close agreement with the values of Reddy [7] and Liew [8] based on the FSDT.

Figs. 1 show the non-dimensional fundamental frequency of the simply supported square plate .

Table 1 The non-dimensional fundamental frequency of the simply supported square plate $\left(0^{\circ} / 90^{\circ} / 90^{\circ} / 0^{\circ}\right)$

\begin{tabular}{llllll}
\hline $\mathrm{a} / \mathrm{h}$ & Method & $\mathrm{E}_{1} / \mathrm{E}_{2}$ & & & \\
\cline { 3 - 6 } & & 10 & 20 & 30 & 40 \\
\hline 5 & Liew[7] & 8.299 & 9.568 & 10.327 & 10.855 \\
& P. Touratier & 8.274 & 9.530 & 10.277 & 10.793 \\
& P. Mantari & 8.326 & 9.617 & 10.387 & 10.920 \\
& P. Karama & 8.281 & 9.542 & 10.292 & 10.811 \\
& P. Levinson & 8.272 & 9.526 & 10.272 & 10.787 \\
10 & Reddy[8] & 9.853 & 12.383 & 13.892 & 15.143 \\
& P. Touratier & 9.830 & 12.221 & 13.868 & 15.113 \\
& P. Mantari & 9.864 & 12.270 & 13.945 & 15.214 \\
& P. Karama & 9.845 & 12.228 & 13.879 & 15.128 \\
& P. Levinson & 9.844 & 12.218 & 13.864 & 15.107 \\
\hline
\end{tabular}

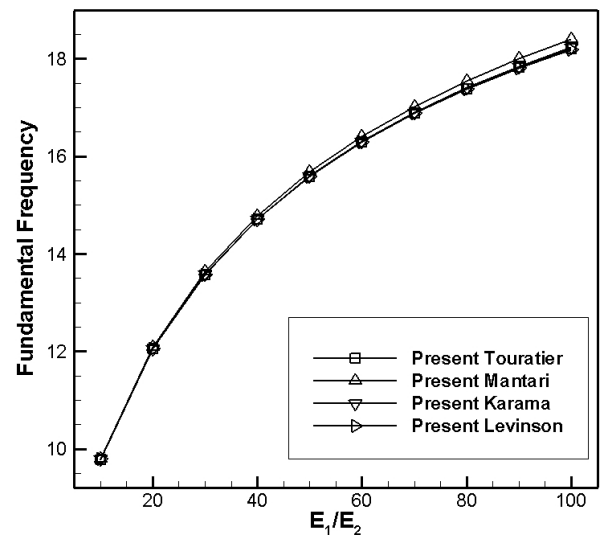

Fig.1 The non-dimensional fundamental frequency of the simply supported pate 


\section{Conclusions}

In this paper, the analysis of various higher-order shear deformation theories for the free vibration of laminated composite plates is presented. A Navier-type analytical method was used to solve the governing differential equations. Natural frequencies of simply supported laminated composite plates are calculated. The results show that Mantari model produces the biggest results.

\section{Acknowledgement}

The Project is sponsored by “Liaoning BaiQianWan talents Program”(No.2014921048)

\section{References}

[1] Sahoo R, Singh BN, A new trigonometric zigzag theory for buckling and free vibration analysis of laminated composite and sandwich plates, Composite Structures. 117 (2014) 316-332.

[2] Ngo-Cong D, Mai-Duy N, Karunasena W, Tran-Cong T, Free vibration analysis of laminated composite plates based on FSDT using one-dimensional IRBFN method, Computers \& Structures, 89 (2011) 1-13.

[3] Touratier M. An efficient standard plate theory. Int J Eng Sci 1991;29(8):901-16.

[4] Mantari JL, Oktem AS, Soares CG. A new higher order shear deformation theory for sandwich and composite laminated plates. Composites: Part B 2012;43:1489-1499.

[5] Karama M, Afaq KS, Mistou S. Mechanical behaviour of laminated composite beam by new multi-layered laminated composite structures model with transverse shear stress continuity. Int J Solids Struct 2003;40:1525-46.

[6] Levinson M. An accurate simple theory of static and dynamics of elastic plates. Mech Res Commun 1980;7:343-350.

[7] Liew KM, Huang YQ, Reddy JN. Vibration analysis of symmetrically laminated composite plates based on FSDT using the moving least square differential quadrature method. Comput Methods Appl Mech Ergrg. 192 (2003) 2203-2222.

[8] Reddy JN. Mechanics of Laminated Composite Plates Theory and Analysis. CRC Press, Boca Raton, 1997. 